\title{
Functional Fractionation of the Stimulus-Driven Attention Network
}

\author{
Suk Won Han and René Marois \\ Department of Psychology, Vanderbilt Vision Research Center, Center for Integrative and Cognitive Neurosciences, Vanderbilt University, Nashville, \\ Tennessee 37240
}

\begin{abstract}
A novel, salient event in the environment powerfully captures attention. This stimulus-driven attentional capture not only includes orienting of attention toward the event, but also an evaluative process to determine the behavioral significance and appropriate response to the event. Whereas a network of human brain regions composed of prefrontal and temporoparietal regions have been associated with stimulus-driven attention, the neural substrates of orienting have never been teased apart from those of evaluative processes. Here we used fMRI to measure the human brain's response to the temporally extended presentations of salient, task-irrelevant stimuli, and found a clear functional dissociation in the stimulus-driven attention network; the anterior insula and cingulate cortex showed transient orienting responses to the onsets and offsets of the stimuli, whereas the temporoparietal cortex exhibited sustained activity throughout event evaluation. The lateral prefrontal cortex was implicated in both attentional and evaluative processes, pointing to its central, integrative role in stimulus-driven attention.
\end{abstract}

Key words: attention; brain networks; fMRI

\section{Introduction}

It has long been recognized that people exhibit an orienting response to the presentation of novel, rare, and salient stimuli ("oddballs") in the environment (Pavlov, 1927; Sokolov, 1963). This orienting response does not only involve a host of physiological responses, it is also accompanied by several attentiondemanding processes (Sokolov, 1963; Kahneman, 1973; Downar et al., 2002). Specifically, once oddballs are detected and attention is switched to them (attentional orienting; Posner, 1980), an evaluative process takes place to determine their identity and potential behavioral relevance (Sokolov, 1963; Kahneman, 1973; Downar et al., 2002). If the oddball is evaluated to be behaviorally relevant, it may be acted upon or avoided. If the oddball is deemed behaviorally inconsequential, attention may be redirected back to the goal-oriented behavior (reorienting of attention).

Whereas it is well established that several cortical networks, including the stimulus-driven attention (SDA) network consisting of the anterior insula (AI), inferior frontal junction (IFJ), and temporoparietal junction (TPJ), and the saliency network comprised of the AI and anterior cingulate cortex (ACC), are coacti-

Received Nov. 27, 2013; revised April 10, 2014; accepted April 13, 2014.

Author contributions: S.W.H. and R.M. designed research; S.W.H. performed research; S.W.H. analyzed data; S.W.H. and R.M. wrote the paper.

This research was partially funded by Vanderbilt CTSA grant to R.M. and a P30-EY008126 grant to the VVRC. We thank Rachel Abeshouse for recruiting and running participants.

The authors declare no competing financial interests.

Correspondence should be addressed to either of the following: Dr Suk Won Han, Department of Psychology,

Chungbuk National University, Republic of Korea, E-mail: suk.w.han@vanderbilt.edu; or René Marois, Department of Psychology, $11121^{\text {st }}$ Avenue South, Nashville, TN 37240, E-mail: rene.marois@vanderbilt.edu.

DOI:10.1523/JNEUROSCI.4975-13.2014

Copyright $\odot 2014$ the authors $\quad 0270-6474 / 14 / 346958-12 \$ 15.00 / 0$ vated when an oddball captures attention in a stimulus-driven manner (McCarthy et al., 1997; Corbetta and Shulman, 2002; Downar et al., 2002; Seeley et al., 2007; Corbetta et al., 2008; Sridharan et al., 2008; Asplund et al., 2010; Menon and Uddin, 2010), the functional contribution(s) of each individual region to stimulus-driven attention is poorly understood. In particular, it remains unknown how such distinct processes as attentional orienting/reorienting and stimulus evaluation are neurally implemented in these networks, as previous neurofunctional models of stimulus-driven attention have not specifically distinguished between them (Serences et al., 2005; Corbetta et al., 2008; Bartolomeo et al., 2012). Whereas previous studies have ascribed attention orienting to the TPJ and IFJ (Corbetta and Shulman, 2002; Corbetta et al., 2008; Asplund et al., 2010; Ptak, 2012), these studies used stimuli that were presented too briefly to temporally separate neural activity associated with each subcomponent process of SDA (Downar et al., 2002; Asplund et al., 2010).

Using fMRI and a temporally extended oddball paradigm, the present study aimed at distinguishing the neural substrates associated with attentional orienting from those of stimulus evaluation. Specifically, by presenting temporally extended oddballs (10-s-long movies) while subjects were engaged in a goaldirected task, we rendered the processes of attentional orienting/ reorienting and stimulus evaluation temporally resolvable with fMRI. In particular, regions involved in attentional orienting/ reorienting should show transient activity, as orienting refers to the transient process of detecting and switching attention to the stimulus (Posner, 1980; Konishi et al., 1998). In contrast, stimulus evaluation, which includes identification and categorization of the event by comparing it with internal representations (McCarthy and Donchin, 1981; Decety and Lamm, 2007; Doricchi et al., 2010), should be sensitive to the contents of the stimuli. 
Hence, as the "oddballness" of the stimuli is temporally extended, evaluation should also be extended, yielding sustained activity. Finally, by presenting all stimuli at fixation, the brain response to oddball events was assessed without extraneous spatial attention shifts or eye movements (Asplund et al., 2010).

\section{Materials and Methods}

\section{Behavioral experiments}

Participants. Twelve adults (6 males, aged 18-24) participated for course credit or monetary compensation in Experiment 1. Another group of 13 adults (5 males, aged 18-24) participated in Experiment 2. The Vanderbilt Institutional Review Board approved the experimental protocol and written informed consent was obtained from each participant.

Design and procedure. The task of Experiment 1 involved searching for targets (images of a dining room and a living room) in a rapid serial visual presentation (RSVP) of distractors (images of outdoor, indoor scenes, or buildings) presented at the center of the screen. A trial lasted $18 \mathrm{~s}$ and consisted of the presentation of up to 144 125-ms-long images subtending $2^{\circ}$ of visual angle. Each distractor image in the RSVP was randomly selected from a pool of 40 distractor images. Although an image could appear more than once in the RSVP, no image was successively repeated. In each trial, participants detected and identified the targets in the RSVP by immediately pressing buttons assigned to each of the two targets. There were a total of 120 trials, which were divided into three trial types: long oddball-target (4 trials), long oddball-no target (6), and searchtarget (110) trials.

In the long oddball-target and long oddball-no target trials, the oddballs consisted of 10-s-long movie clips presented either 4 or $6 \mathrm{~s}$ after trial onset. Ten such oddballs were presented in each experimental session, and they consisted of a car accident, an earthquake, fireworks, a building explosion, fast-moving roller coasters, overturning ships, moving toys, a burning tank, a dogfight of jet-fighters, and a laptop commercial. The movies were downloaded from the World Wide Web, and edited so that neither text, humans, nor animals were shown.

In the four long oddball-target trials, a target was presented either at lag 2 or at lag 13 from the oddball offset. These trials served to demonstrate that attention was sustained on the oddball stimulus throughout its presentation duration. Given that there were only two trials per lag per subject (and hence individual target accuracy at a given lag could either be 0,50 , or $100 \%$ ), the effect of oddball presentation on target performance was assessed by applying the nonparametric Wilcoxon signedrank test. The remaining long oddball trials were identical to the long oddball-target trials described above except that no target was presented after the oddball offset (long oddball-no target trials).

In the remaining 110 trials, which did not include any oddball stimulus, a variable number of targets $(1,2$, or 3$)$ were imbedded in the RSVP of distractors (search-target condition). The first target (T1) was presented 2, 4, 6, 8, 10, or $14 \mathrm{~s}$ after the onset of the trial. The second target (T2), when presented, followed the first target with a $4,8,10$, or $12 \mathrm{~s}$ interval, whereas the third target (T3) was presented $15 \mathrm{~s}$ after the trial onset.

Experiment 2 was performed to examine whether any deficit in target processing in Experiment 1 was due to sustained attention to the oddball or to the abrupt transient between the oddball offset and the RSVP of distractors. Experiment 2 was identical to Experiment 1 except that a single oddball randomly chosen among the oddballs used in Experiment 1 was presented 10 times; each participant saw a different oddball.

\section{fMRI experiments}

\section{fMRI Experiment 1}

Participants. Fourteen adults (5 males, aged 20-32) participated for monetary compensation. The Vanderbilt Institutional Review Board approved the experimental protocol and written informed consent was obtained from each participant.

Design and procedure. A similar paradigm to the behavioral experiments was used except that there were a total of 180 trials, which were divided into six trial types; in addition to the long oddball-target (4 trials), long oddball-no target (6), and search-target (98) trials as in the behavioral experiments, there were dual-short oddball (6), single-short oddball (6), and search-no target (60) conditions.

Whereas the long oddball-target trials served to replicate the findings of the behavioral experiment in the scanner, the long oddball-no target trials were used for fMRI analyses to examine the neural activity associated with the long oddballs without contamination by target presentations or motor responses. In the conditions containing the long oddballs, the same set of oddball movies used in the behavioral pilot testing were presented for 10 participants, whereas the other four participants were shown another set of 10 oddballs composed of abstract animations (e.g., continuously transforming fractals, molecular polymerization, swirling waves, constantly rotating color patches in random direction, evolving line drawings of geometric shapes, dynamically transforming objects, moving flashlight in random direction, or continuously evolving colored geometric shapes).

Each of the six "dual-short oddball" trials included two 1-s-long static oddball images (the 12 distinct images subtended $2^{\circ}$ of visual angle and consisted of abstract images such as random color patches, an object resembling fire flames, an electron micrograph, an array of several abstract objects) separated by an $8 \mathrm{~s}$ interval during which task-related stimuli (distractors) were presented. This dual-short oddball condition was included to provide a reference for the hemodynamic response to be expected of a given brain region that responds to the onset and offset of the 10-s-long oddballs but not to its sustained presentation.

Six other trials included a single presentation of a 1-s-long static image as oddball (single-short oddball condition; all six distinct images were used). These trials served two purposes. First, they prevented the presence of a short oddball to predict the occurrence of a second one, thereby further ensuring that the second of the two oddballs in the dual-short oddball trials (see above) was attention grabbing. Second, they were used to define regions of interest (ROIs; see fMRI methods, below).

Finally, there were 60 trials in which neither oddball nor target was presented during the RSVP of distractors (search-no target condition). This condition served to isolate the brain activity associated with goaldirected search without contamination by the target or motor responses.

fMRI methods. Anatomical 2D and 3D high-resolution T1-weighted images were acquired with conventional parameters on a 3T Philips scanner at the Vanderbilt Institute of Imaging Sciences. For the functional scan, 33, $3.5 \mathrm{~mm}$ axial slices ( $0.5 \mathrm{~mm}$ skip; $3.75 \times 3.75 \mathrm{~mm}$ in-plane) were taken parallel to the AC-PC line (TR, $2000 \mathrm{~ms}$; TE, $35 \mathrm{~ms}$; FA, 79 ; FOV, $240 \mathrm{~mm}$ ), for a total of 191 brain volumes per fMRI run. There were 12 functional runs, each of which included 15 trials. Trials were separated by a blank interval of variable duration that follows an exponential distribution ( 9 trials $\times 4 \mathrm{~s}, 4$ trials $\times 8 \mathrm{~s}, 2$ trials $\times 12 \mathrm{~s})$ to facilitate deconvolution analysis of the BOLD responses (Serences, 2004). Imaging data were analyzed using Brain Voyager QX 2.3 and custom software written in MATLAB. Data preprocessing included slice scan time correction, 3D motion correction, linear trend removal, and spatial smoothing with a $6 \mathrm{~mm}$ Gaussian kernel (FWHM). All functional data of each participant were aligned to the first functional run, and coregistered to each individual's anatomical T1-weighted image. Functional and anatomical data were transformed into standardized Talairach space (Talairach and Tournoux, 1988).

ROIs were defined on statistical parametric maps (SPMs) using two standard approaches to isolate the stimulus-driven attention network: oddball and target processing. This is because nearly all of the core regions in the SDA and saliency network are not only involved in processing of rare task-irrelevant stimuli, but also engaged in the detection of infrequent, behaviorally relevant stimuli and targets (Downar et al., 2002; Seeley et al., 2007; Corbetta et al., 2008; Eckert et al., 2009; Asplund et al., 2010; Menon and Uddin, 2010; Nelson et al., 2010), and at least for the AI and ACC, in the performance of goal-oriented tasks and cognitive control (Eckert et al., 2009; Menon and Uddin, 2010; Nelson et al., 2010; Ham et al., 2013).

First, the single-short oddball trials were used to isolate regions most responsive to oddball presentations by contrasting activity in these trials with activity in the search-no target trials. Regressors were defined for each trial type and convolved with a double gamma function (SPM2; http://www.fil.ion.ucl.ac.uk/spm). Then, a group random effect contrast 
Table 1. List of ROIs defined in Experiment 1

\begin{tabular}{lrrrr}
\hline & & \multicolumn{3}{c}{ Talairach coordinates } \\
\cline { 4 - 5 } ROI name & Mean $t$ value & \multicolumn{1}{c}{$Y$} & $Z$ \\
\hline Single-short oddball-defined ROls & & & & \\
$\quad$ Left IFJ & 3.17 & -49 & 19 & 18 \\
Right IFJ & 3.13 & 45 & 14 & 19 \\
Left TPJ & 3.05 & -55 & -46 & 13 \\
Right TPJ & 3.04 & 49 & -54 & 17 \\
Left Al & 5.58 & -30 & 18 & 0 \\
Right AI & 2.97 & 28 & 16 & 0 \\
ACC & 3.15 & -2 & 15 & 44 \\
Target-defined ROIs & & & & \\
Left Al & 6.11 & -30 & 15 & 3 \\
Right Al & 4.87 & 32 & 13 & 2 \\
ACC & 3.86 & 4 & 15 & 36 \\
Left IFJ & 3.23 & -45 & 3 & 22 \\
Right IFJ & 5.16 & 44 & 5 & 26 \\
Left TPJ & -11.35 & -48 & -63 & 22 \\
Right TPJ & -9.25 & 48 & -59 & 22 \\
Left FEF & 4.40 & -27 & -7 & 45 \\
Right FEF & 4.32 & 32 & -2 & 47 \\
Left IPS & 4.71 & -31 & -58 & 43 \\
Right IPS & 4.56 & 31 & -58 & 43 \\
\hline
\end{tabular}

was run to isolate regions involved in oddball processing. The resulting SPM was corrected for multiple comparisons, using a cluster filter of 25 contiguous voxels, yielding a mapwise error rate of $p<0.05$ (Forman et al., 1995). Each ROI was defined as the peak voxel and surrounding areas up to $1.33 \mathrm{~cm}^{3}$ of the region (Dux et al., 2006). This group-based SPM contrast yielded significant activation in the IFJ and TPJ. However, partly due to the low power of this contrast given the restricted number of trials in the single-short oddball, other brain regions previously implicated in stimulus-driven attention and salience processing, namely the AI and ACC (Downar et al., 2002; Kiehl et al., 2005; Seeley et al., 2007; Blackford et al., 2010; Menon and Uddin, 2010), were not significantly activated above threshold.

To isolate the AI and ACC, a second ROI-defining SPM contrast based on a regressor for target processing was performed in each individual subject $(q(\mathrm{FDR})<0.05$, using the peak voxels and surrounding area up to $\left.1.33 \mathrm{~cm}^{3}\right)$. To confirm that the AI and ACC defined with the target regressor are the same regions implicated in oddball processing, we also isolated these regions in individual subjects using the short oddballs (both single and dual) versus search-no target contrast. Based on the SPM of 9 subjects that showed robust AI and ACC activations $(q(\mathrm{FDR})<$ 0.05 ), we defined a group-based ROI and then probed this ROI for long oddball activation in all 14 subjects. As shown in Table 1 and Figure 2, insets, the oddball-defined ACC and AI ROIs not only spatially overlapped with those defined with the target regressor, their activation time courses were also very similar.

We also used the target regressor to determine whether the IFJ and TPJ results were the same as with the $1 \mathrm{~s}$ oddball regressor (for the target regressor, the TPJ was defined as a region associated with negative $\beta$ weights (Asplund et al., 2010), given that the TPJ tends to be deactivated during goal-directed behaviors such as searching for targets and attending to task-relevant information (Raichle et al., 2001; Greicius et al., 2003; Todd et al., 2005; Shulman et al., 2007; Harrison et al., 2008). Importantly, the TPJ and IFJ results of fMRI Experiments 1 and 2 are the same regardless of whether the ROIs were defined with the group-based, single-short oddball contrast or the individual-based, target contrast. The TPJ and IFJ data from the single-short oddball-defined ROIs are presented in the Results section because they directly reflect oddball processing. Finally, the target regressor also allowed the isolation of core components of the dorsal attention network, the intraparietal sulcus (IPS), and frontal eye field (FEF) ROIs.

In addition to the above ROIs, the amygdala was also probed because of its potential involvement in SDA (Wright et al., 2003; Kiehl et al., 2005; Blackford et al., 2010; Balderston et al., 2011). The amygdala was defined anatomically by manually tracing the border of the region, excluding the nearby structures (e.g., hippocampus and putamen).

For ROI analyses, event-related time courses of the BOLD signal for each participant and condition were estimated using a deconvolution analysis (using the 20 volumes immediately following the trial onsets). Then, these time courses were averaged across participants, yielding group-averaged time courses. As no hemispheric difference was found $(p>0.3)$, timecourse of bilateral ROIs were collapsed to increase statistical power (Asplund et al., 2010). To be noted, given that all ROIs were defined using trials that contained long oddballs, ROI selection was statistically independent from subsequent time course analyses.

Given that oddball processing is performed in the context of a goaloriented behavior (target searching), to specifically isolate the brain response to the oddballs we subtracted away activity associated with the goal-directed search process. Specifically, the time course for search activity (search-no target condition) was subtracted from the time course for the trials containing oddballs but no targets (dual-short oddball; Asplund et al., 2010).

Even though it is presumed that there is no search-related activity during the extended oddball presentation, the same subtraction was also applied to the time course for the long oddball-no target trial activity for consistency. Importantly, the subtraction did not change the temporal activity profile (transient vs sustained) of the long oddball.

Once time courses of the BOLD response to oddballs were constructed, we statistically assessed whether those responses were doublepeaked (transient) or single-peaked (sustained) for the dual-short oddball and long oddball-no target conditions. First, the peak volumes whose activities correspond to the onset and offset of the oddball were determined. The onset-related peak volume was defined as the volume with the greatest signal amplitude between the third and seventh volumes immediately following the onset of the oddball (4-12 s from the oddball onset; Dux et al., 2006). The offset peak volume was also defined in a similar way except that the volumes following the offset of the oddball were used (14-22 s from the oddball onset). The amplitudes of the onset and offset peak volumes were then compared with that of the volume corresponding to the middle point between those peaks, using paired $t$ tests.

\section{fMRI Experiment 2}

Whereas fMRI Experiment 1 was aimed at distinguishing brain regions showing transient activity from those exhibiting sustained activity, fMRI Experiment 2 addresses whether the latter brain regions also show transient activity. Specifically, if a region is involved in both the transient and sustained components of stimulus-driven attention, that region's transient activity may be swamped by the large sustained activity. To reveal such a transient activity, the same long oddball was repeatedly presented throughout the experimental session to attenuate the sustained activity associated with the oddball. A power analysis using the data from fMRI Experiment 1 suggested that given the high effect size of presenting the long oddball (Cohen's $d>1.10$; see Results), an $N$ of $\sim 6$ is sufficient to detect a transient, double-peaked response at the statistical power level of 0.80 (Cohen, 1988).

Based upon this power analysis, six participants (4 males, aged 19-35) were scanned in this experiment. All the behavioral and imaging protocols were identical to those of fMRI Experiment 1 except for the following modifications. The same long oddball was presented 20 times of a total of 135 trials. Among these 20 oddball trials, there were 10 long oddball-no stimulus trials, in which a fixation period followed the offset of oddballs (see below). The other 10 oddball trials were either long oddball-no target trials (8 trials) or long oddball-target trials (2) in which the oddballs were followed by the RSVP task. In the long oddball-target trials, a target was presented at either lag 2 or lag 13 from the oddball offset. Participants could expect whether an oddball would be followed by the search task or by no task at all because all 10 trials of a given trial type were presented before the presentation of the 10 trials of the other trial type (e.g., the first 10 long-oddballs were followed by fixation, whereas the last 10 oddballs were followed by the RSVP task, with this order counterbalanced between subjects). The introduction of 10 long oddball-no stimulus trials was done to examine whether the oddball offset activity is 

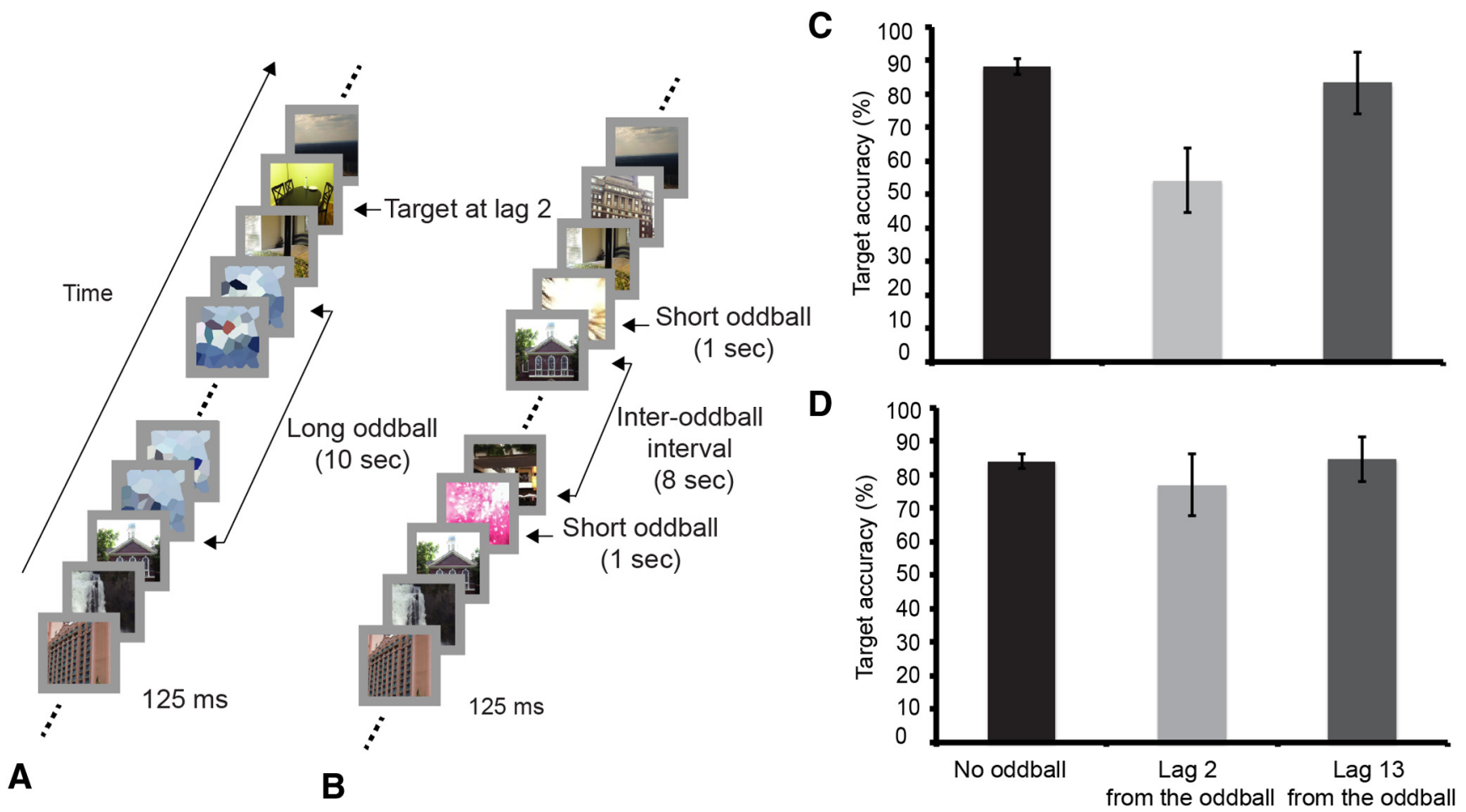

Figure 1. Trial design and behavioral results. $\boldsymbol{A}$, Trial of behavioral Experiment 1 that contains a long oddball and target (long oddball-target trial). When present in a long oddball trial, the target could be at lag 2 (depicted) or lag 13 from oddball offset. $\boldsymbol{B}$, Trial of fMRI Experiment 1 that contains two short oddballs separated by an 8 s interval (dual-short oddball trial). $\boldsymbol{C}$, Results of behavioral Experiment 1 (distinct oddballs). Each graph shows target identification performance in trials that contain no oddball and in trials in which the target appeared at lag 2 or 13 following the oddball presentations. $\boldsymbol{D}$, Results of behavioral Experiment 2 (repeated oddball). Error bars represent SEM.

signaling any changes in environmental conditions (as would be expected at the offset of an oddball followed by a fixation period) or a change that is specifically behaviorally relevant (as would be expected at the transitions between oddballs and the search task). Given that the results of these long-oddballs followed by fixation are similar to the results of the long-oddballs followed by the search task, only the latter is presented in the paper.

Unlike in the first fMRI experiment, there were neither single-short nor dual-short oddballs in Experiment 2. There were, however, searchtarget trials (65) and search-no target trials (50). All ROIs were thus individually defined using target regressors as explained in Experiment 1. Extraction of time courses and statistical assessment of the activity patterns were also performed as in Experiment 1. Probing of the IFJ and TPJ ROIs using the Talairach coordinates derived from the single-oddball regressor SPM of Experiment 1 yielded the same pattern of activation as probing the individually defined ROIs with the target regressor in Experiment 2.

Although statistical assessment of the single- or double-peaked activity patterns were performed as in Experiment 1, we also compared activation profiles of each ROI across the two experiments. Specifically, a two-way ANOVA with time (11 TRs from the oddball onset) as a withinsubject factor and Oddball type (distinct vs repeated) as a betweensubject factor was applied for each ROI to examine how the activation patterns in the ROIs are modulated by the repeated oddball presentation. Furthermore, to examine whether activity modulation by oddball type differs across regions, a three-way ANOVA with ROI as a within-subject factor, in addition to the two other factors described above (time and oddball type), was also implemented.

\section{Results}

\section{Behavioral experiments}

First, we behaviorally tested in 12 participants whether attention is sustained on the oddball stimuli throughout their extended presentations. The experimental task involved searching for targets (images of a dining or living room) in a rapid serial visual presentation (RSVP) of distractors (images of indoor, outdoor scenes, or buildings), with each stimulus presented for $125 \mathrm{~ms}$ during an 18-s-long trial. In 10 of a total of 120 trials, video-clip oddballs interrupted the RSVP stream for $10 \mathrm{~s}$ before the RSVP stream resumed (Fig. 1A). In four of these long oddball trials, a target followed the offset of the oddball at either lag 2 or at lag 13. If attention is maintained on the extended oddballs throughout their presentation duration, target accuracy should be worse when the target follows the oddball offset at lag 2 than at lag 13 because the short lag should leave too little time for attention to be redirected from the oddball to the RSVP task, whereas the long lag should (Asplund et al., 2010). By contrast, if attention is not sustained on the oddball, then target performance should already be high at lag 2 .

As shown in Figure $1 C$, target accuracy was worse at lag 2 than at lag 13 , suggesting that attention was sustained on the oddball (Wilcoxon signed-rank test, $p<0.05$ ). These results rule out the possibilities that attention was directed to searching for targets during oddball presentation or to expecting the oddball offset at $10 \mathrm{~s}$, for were these the cases lag 2 performance should not have shown any deficit. Yet another alternative interpretation to this result, however, is that it is the transition between the oddball offset and RSVP stream that impaired target processing rather than sustained attention to the oddball. To address this issue, we ran a second behavioral experiment $(n=13)$ in which the same long oddball was repeatedly presented 10 times. Because its content should rapidly become familiar to the participants with iterated presentations, the repeated oddball should not sustain much of the participants' attention throughout its presentation, and hence target performance at Lag 2 should not be worst than at lag 13. The results confirmed that prediction (Wilcoxon signed-rank test, $p>0.59$; Fig. $1 D$ ). Finally, it follows from the above considerations that lag 2 performance should be worse in Experiment 1 

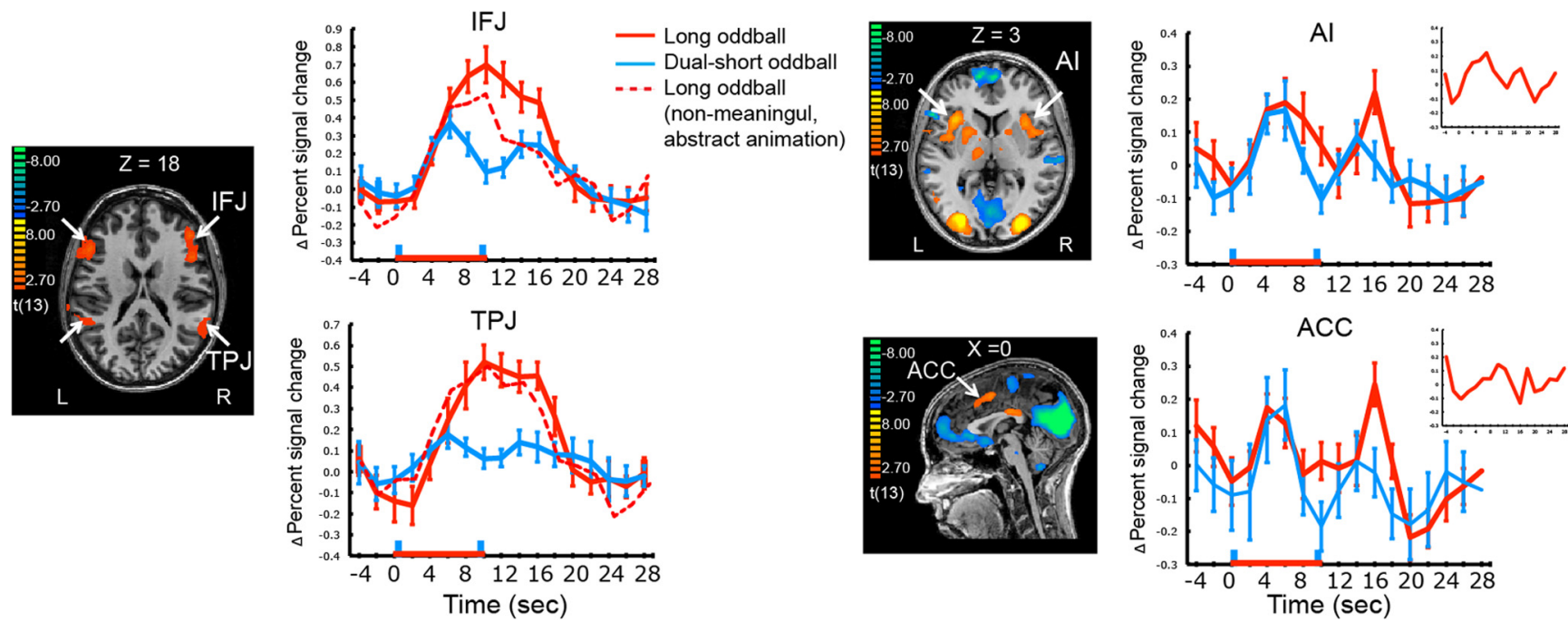

Figure 2. SPMs showing IFJ, TPJ, Al, and ACC. The first and second blue vertical bars (at time point zero and nine) in the time courses indicate the first and second short (1 s) oddballs in the dual-short oddball condition. The red stippled lines are activation time course of the IFJ and TPJ when the oddballs consisted of only nonmeaningful, abstract movies. The insets in the Al and ACC time course plots show the activation profiles of these ROls when defined by contrasting the single-short and dual-short oddball trials with the search trials. The red horizontal line indicates the presentation of 10 s long oddballs. Error bars represent SEM.

than Experiment 2, a prediction borne out by direct statistical comparison (Mann-Whitney test for independent samples, $p<$ 0.05 , one-tailed).

Together, these finding suggest that the lag 2 deficit in Experiment 1 was due to sustained attention to the oddball rather than to perceptual/cognitive transitions between oddball and RSVP.

\section{fMRI Experiment 1: distinct oddballs}

The first fMRI experiment $(n=14)$ used a similar paradigm to the first behavioral experiment except that in addition to the four long oddball-target trials, six long oddball-no target trials and 98 search-target trials, there were six single-short (1 s) oddball trials for ROIs definition, six dual-short oddball (two 1-s-long oddballs $8 \mathrm{~s}$ apart) trials to provide a reference for potential transient activity with long oddball onsets and offsets, and 60 search-no target trials to provide a baseline for search-related activity. The behavioral data acquired during the scans were very similar to those acquired outside the scanner; target accuracy in the long oddball-target trials was worse at lag 2 than at lag 13 (Wilcoxon signed-rank test, $p<0.05$ ).

To examine the BOLD response of the core SDA regions to oddball presentations, the AI, ACC, IFJ, and TPJ were first functionally localized using both Single-short oddball- and targetrelated activity. We then statistically assessed whether the BOLD response pattern to the long oddball in each ROI was single- or double-peaked by comparing the response amplitude in the middle of the oddball to the amplitudes at the onset and offset of the oddball and to the baseline (see Materials and Methods).

As shown in Figure 2, the IFJ and TPJ showed a large sustained (single-peaked) pattern of activity throughout the presentation of the long oddballs. Specifically, amplitude at the middle point of the BOLD response was not only above baseline in both regions $\left(p<6.5829 \times 10^{-4}\right.$, Cohen's $\left.d>2.48\right)$, it was also not significantly different from the offset amplitude $(p>0.11)$. These sustained activations were not due to the sluggishness of the hemodynamic responses in these regions as the dual-short oddball trials yielded transient activity; the peak amplitudes of each short oddball were greater than the amplitude at the middle point between the two peaks $\left(t_{(13)}>3.29, p<0.005\right.$, Cohen's $d>$
0.45) and this middle point amplitude was indistinguishable from baseline (zero; $p>0.18$ ). These patterns were consistent, regardless of whether these ROIs were defined with the oddball or target regressors.

In stark contrast to the IFJ and TPJ, the AI and ACC showed double-peaked responses to the long oddball; the amplitudes at the onset and offset peaks were greater than that at the middle point $\left(t_{(13)}>4.71, p<4.10 \times 10^{-4}\right.$, Cohen's $\left.d>1.10\right)$, which was not significantly different from zero $(p>0.2)$. As expected, the AI and ACC showed double-peaked patterns of activity in the Dual-short oddball trials, with greater activities at the onsets of the first and second peaks than at the middle point $(p<0.008$, Cohen's $d>0.47$ ), but baseline-level activity at the mid-point $(p>0.87)$. Finally the transient responses in the AI and ACC and sustained responses in the IFJ and TPJ were replicated in an independent dataset obtained using a similar, extended oddball paradigm, further confirming the reliability of the present results (Han and Marois, 2013; Annual Meeting of Society For Neuroscience).

It is conceivable, however, that the transient responses in $\mathrm{AI}$ and ACC result from rapidly adapting hemodynamic responses to sustained neural activity in these brain regions rather than genuinely reflecting transient neural activity. This possibility was ruled out, however, by observing in these brain regions a single sustained hemodynamic response to pairs of targets presented at an interval that is short enough (4s) to produce a response that lasts much longer than a response to individual target presentations (Fig. 3). Specifically, with the $8 \mathrm{~s}$ intertarget interval, the $\mathrm{BOLD}$ response clearly showed a double-peak response in both the AI and ACC; comparisons of BOLD amplitude between time point 4 (i.e., $4 \mathrm{~s}$ after first target presentation) and time point 8 (i.e., $8 \mathrm{~s}$ after first target presentation) yielded greater activity at time $4\left(p<1.1280 \times 10^{-4}\right)$, just as comparisons between time 8 and time 12 (i.e., $4 \mathrm{~s}$ after second target presentation) yielded greater activity at time $12\left(p<3.2223 \times 10^{-4}\right)$. By contrast, the signal persisted as a single peak during the same period of time when targets were separated by $4 \mathrm{~s}$ in both AI and ACC; comparisons between time 4 (i.e., $4 \mathrm{~s}$ after first target presentation) and time 8 (i.e., $4 \mathrm{~s}$ after second target presentation) showed no sig- 

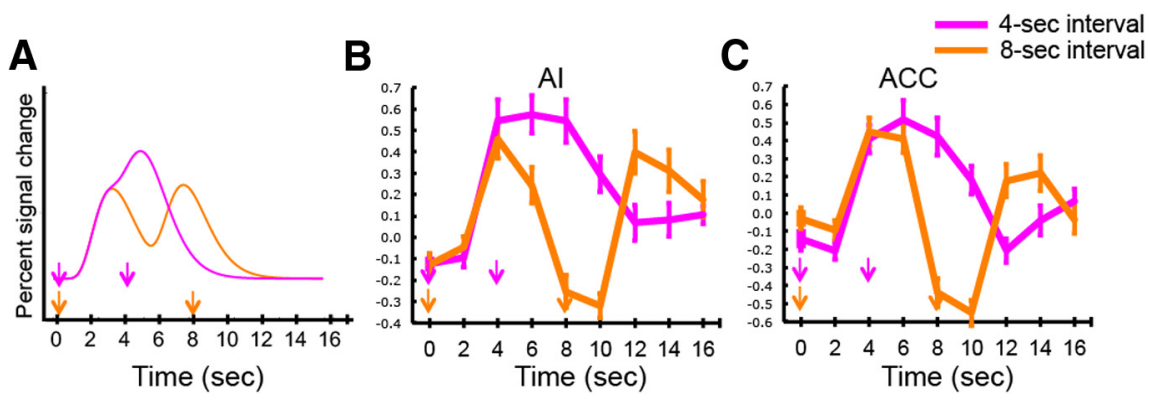

Figure 3. Sustained BOLD response in Al and ACC with multiple target presentations. $\boldsymbol{A}$, Modeled hemodynamic responses to targets separated either by a 4 or 8 s interval. $\boldsymbol{B}$, Time courses of activation of the Al for target presentations at 4 and $8 \mathrm{~s}$ intervals. C, Time courses of activation of the ACC for target presentations at 4 and $8 \mathrm{~s}$ intervals. The Al and ACC showed transient, doublepeaked patterns of activities during the long oddball presentation.

nificant difference $(p>0.88)$, followed by significantly less activity at time 12 (i.e., $8 \mathrm{~s}$ after second target presentation) than at time $8\left(p<8.949 \times 10^{-4}\right)$.

Together, the above findings suggest a functional dissociation within the stimulus-driven attention network in the face of a temporally extended oddball, with the AI (and ACC) transient activity at oddball onsets/offsets consistent with an attention orienting function, and the sustained IFJ and TPJ activity indicative of an evaluative process. The sustained IFJ and TPJ activities are remarkable given that it has been assumed that the core nodes of the stimulus-driven attention network are involved in attentional orienting (Corbetta and Shulman, 2002; Corbetta et al., 2008; Bartolomeo et al., 2012; Ptak, 2012). Were this the case, every region in the network should have shown a transient response profile. Contrary to predominant models of stimulus-driven attention, the current finding suggest that each node of the stimulus-driven attention network has distinct functions, and that some of these functions are not related to attentional orienting per se.

\section{Analysis of sustained activity in the TPJ}

An alternative interpretation for the TPJ's, and perhaps also IFJ's, sustained response with the extended oddballs is that it reflects its known involvement in social attribution and mentalization (Frith and Frith, 2006; Hampton et al., 2008). That is, some of the oddball movie clips included human-powered, real-world situations (e.g., aerial combat of fighter jets), which may have evoked the process of inferring the mental states of the human agents that controlled the objects or events even if the agents were not visible in the movie clips. To address this issue, we separately analyzed the data from the four participants who were only exposed to nonmeaningful abstract animations that were devoid of socio-affective content. These four participants still showed robust sustained activity in the TPJ (and IFJ; Fig. 2, stippled line), suggesting that this activity is not caused by social evaluative or mentalizing processes.

We also considered the possibility that the increased TPJ activity during the long oddball presentations simply reflected the release of suppression that is usually imposed on this region during goal-directed behavior (Raichle et al., 2001; Greicius et al., 2003; Todd et al., 2005; Shulman et al., 2007). That is to say, because there was no goal-directed behavior during the long oddball presentations, the TPJ might have entered into a "default mode” or resting state (Raichle et al., 2001; Greicius et al., 2003), thereby elevating its activity compared with search-related activity. This release from suppression could then be erroneously construed as activation in response to the oddball stimulus. If this is the case, then TPJ activity during the oddball presentation is expected to be comparable to that during the intertrial fixation interval, as there is also no goal-directed behavior during that period. Contrary to this expectation, TPJ activity during the long oddball presentation was far greater than during the fixation period (Fig. $4 ;\left(t_{(13)}=4.00, p=\right.$ 0.0015 , Cohen $d=1.56$; paired $t$ test between volumes with the greatest signal amplitude; similar results were obtained in IFJ). This result indicates that the oddball-related activation is not simply due to release from suppression associated with the interruption/cessation of a goal-oriented task.

It is also possible that TPJ activity could be merely stimulus-driven, responding to any presentations of attended stimuli, rather than reflecting event evaluation. Were this the case, the TPJ should be activated during the search-no target trials as these trials included the RSVP of familiar distractors but no targets or oddballs. By contrast, if the TPJ activity reflects stimulus evaluation, then it should not be activated in those trials, as the brief presentations of familiar distractors should evoke little or no evaluative process. Consistent with the latter prediction (Fig. 5), the TPJ was suppressed during these trials, further pointing to an evaluative function of the TPJ. By contrast, the IFJ, FEF and IPS all showed activations in the search no-target trials, a result that is expected because these regions are known to be involved in goal-directed attention, which should be deployed during the search process (Asplund et al., 2010). This latter finding also rules out another alternative interpretation of TPJ sustained activity with oddball presentations, which is that it reflects attention to the stimulus event per se, rather than its evaluation. After all, evaluation of the temporally extended oddball likely requires that attention be maintained onto the stimulus. However, it is well known that this region is deactivated during sustained attention (Raichle et al., 2001; Greicius et al., 2003; Todd et al., 2005), and as mentioned above we observed suppressed TPJ activity during the search no-target trials (Fig. 5). Finally, when we probed this region with a Posner endogenous cuing task that required sustained attention to a location in anticipation of target presentation but no stimulus evaluation, the TPJ was deactivated whereas the frontal eye fields (FEFs; along with the IFJ and IPS) were activated (B.J. Tamber-Rosenau, C.L. Asplund, and R. Marois, unpublished observations).

Together, these analyses provide further evidence that the TPJ's sustained response during the oddball presentation is specifically associated with an evaluative process rather than attentional processes per se.

\section{fMRI Experiment 2: repeated oddball}

Although the first experiment could successfully distinguish brain regions showing transient activity from those exhibiting sustained activity, it does not address whether the latter brain regions also show transient activity. This is because any transient activity could be swamped by a large sustained response, thereby concealing any transient activity in these region(s). To address this issue, we repeatedly presented the same long oddball throughout the experimental session, as such repeated presentation attenuates the requirement for a sustained attention-based evaluative process as the contents of the oddball become familiar (Fig. 1). However, the onset and offset of the oddball should still capture attention, as the former is an infrequent and nonpredic- 


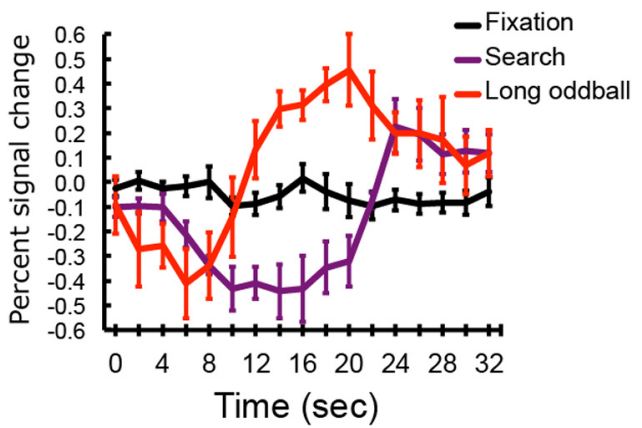

Figure 4. Time courses of TPJ activity in the search-no target, long oddball-no target trials, and during the $12 \mathrm{~s}$ fixation (intertrial interval) periods. The onset of a trial or fixation period is at time point zero and the oddball onset is at time 4.

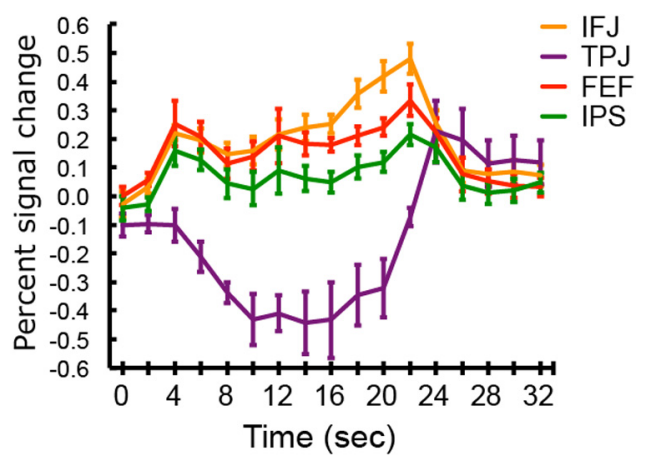

Figure 5. Activation time courses of the IFJ, TPJ, FEF, and IPS during the search no-target trials. During these trials, only the RSVP of distractors was presented without targets and oddballs.

tive event and the latter is a behaviorally significant one, indicating the resumption of goal-directed search. Hence, if the IFJ and TPJ are engaged by these transitory phases of oddball presentations, they should now be manifest.

An analysis of the behavioral data acquired in the scanner showed that there was no difference in target accuracy between the lag 2 and lag 13 from the offset of the repeatedly presented oddball $(p>0.77)$ consistent with the behavioral pilot testing and attesting to the notion that the repeated oddball did not capture attention throughout the duration of its presentations. The imaging results showed that the AI and ACC were transiently activated, consistent with Experiment 1 (Fig. 6); the BOLD responses were greater at the onset and offset volumes than that the middle point volume ( $p<0.05$, Cohen's $d>0.94)$, with the latter not being different from baseline $(p>0.44)$. Consistent with this, when a two-way ANOVA with Time (11 TR) as a within-subject factor and oddball-type (distinct vs repeated) as a between-subject factor was applied to the AI and ACC data, neither the main effect of oddball-type, nor the interaction between the two factors was significant $(p>0.74)$, whereas the main effect of time was significant $(p<0.005)$. The TPJ activity was also similar with that of Experiment 1 ; it showed a single-peaked response ( $p>0.74$, paired $t$ test between the middle point and offset amplitudes) that was significantly above baseline $(p<$ 0.005 , Cohen's $d=0.98$ ), although with markedly reduced amplitude and duration (significant main effects of experiment and time, and an interaction between time and experiment $(p<$ 0.005).

Remarkably, the IFJ, which showed a sustained response to the presentations of distinct oddballs in Experiment 1, now ex- hibited a double-peaked response with the repeated presentation of the same oddball; the onset and offset peak amplitudes were greater than that at the middle point $\left(t_{(5)}>2.84, p<0.05\right.$, Cohen's $d>1.31)$, which was not significantly above baseline $(p>$ $0.25)$. As assessed from the power analysis using data from Experiment 1 (see Materials and Methods), the power to detect transient onset- and offset-related responses with the present small sample size was $\sim 0.86$, suggesting that the current paradigm was sensitive enough to discern the brain region's response profile. The two-way ANOVA applied to the IFJ data also revealed a significant interaction between time and oddball-type $\left(F_{(10,180)}=6.10, p<5.64 \times 10^{-8}\right)$, a main effect of time $(p<$ $\left.3.03 \times 10^{-9}\right)$, and a marginal effect of oddball-type $(p=0.063)$.

This functional dissociation across regions was further confirmed by a three-way ANOVA with time (11 TRs from the oddball onset) and regions (AI, ACC, IFJ, and TPJ) as within-subject factors and oddball-type (distinct vs repeated) as a betweensubject factor. The main effects of region and time and the threeway interaction were highly significant $\left(p<5.18 \times 10^{-5}\right)$. We then examined pairwise three-way interactions for all the possible pairs of ROIs (AI vs ACC, AI vs IFJ, AI vs TPJ, ACC vs IFJ, ACC vs TPJ, and IFJ vs TPJ). There was no three-way interaction when the AI and ACC data were analyzed $(p>0.80)$, which further confirms that these two regions' activities were consistent across experiments. There were highly significant three-way interactions when the IFJ data were paired with either the AI, ACC, or TPJ data $\left(p<1.11 \times 10^{-4}\right)$, because only the IFJ response pattern changed from a single-peaked response in Experiment 1 to a double-peaked one in Experiment 2, whereas other regions' temporal patterns were consistent across experiments. In line with this, when the TPJ data were paired with either the AI data or ACC data, there was no significant three-way interaction $(p>$ $0.30)$.

These analyses reveal that the main results of Experiment 1 (double-peaked responses of the AI and ACC) were successfully replicated in Experiment 2. Similarly, together with Experiment 1, the results of Experiment 2 point to an evaluative role for the TPJ: the diminished demands for sustained evaluation with repeated oddball presentations reduced and shortened TPJ activity, with the residual activity likely reflecting evaluation of the unexpected oddball onset. These results, however, do not entirely exclude the possibility that the TPJ may also be engaged in orienting (but not reorienting), as its activation following oddball onset could include orienting as well as evaluative processes. That being said, the findings that the TPJ did not show peaks at both oddball onsets and offsets and that its amplitude and duration is affected by the oddball content suggests that the primary, if not unique, function of this brain region may be in event evaluation.

Finally, diminished processing demands of the repeated oddball in Experiment 2 unmasked onset- and offset-related responses in the IFJ that were swamped by the sustained activation in Experiment 1. This finding implies that the IFJ is associated with both the transient and sustained components of oddball processing, most likely reflecting attentional orienting and evaluation-based attentional demands throughout oddball presentations.

\section{Dorsal goal-directed attention network}

Given the behavioral evidence that the distinct long oddballs of Experiment 1 are attended throughout their presentation duration (Fig. 1), we predicted that presentation of these oddballs would be associated with sustained activity in regions implicated 

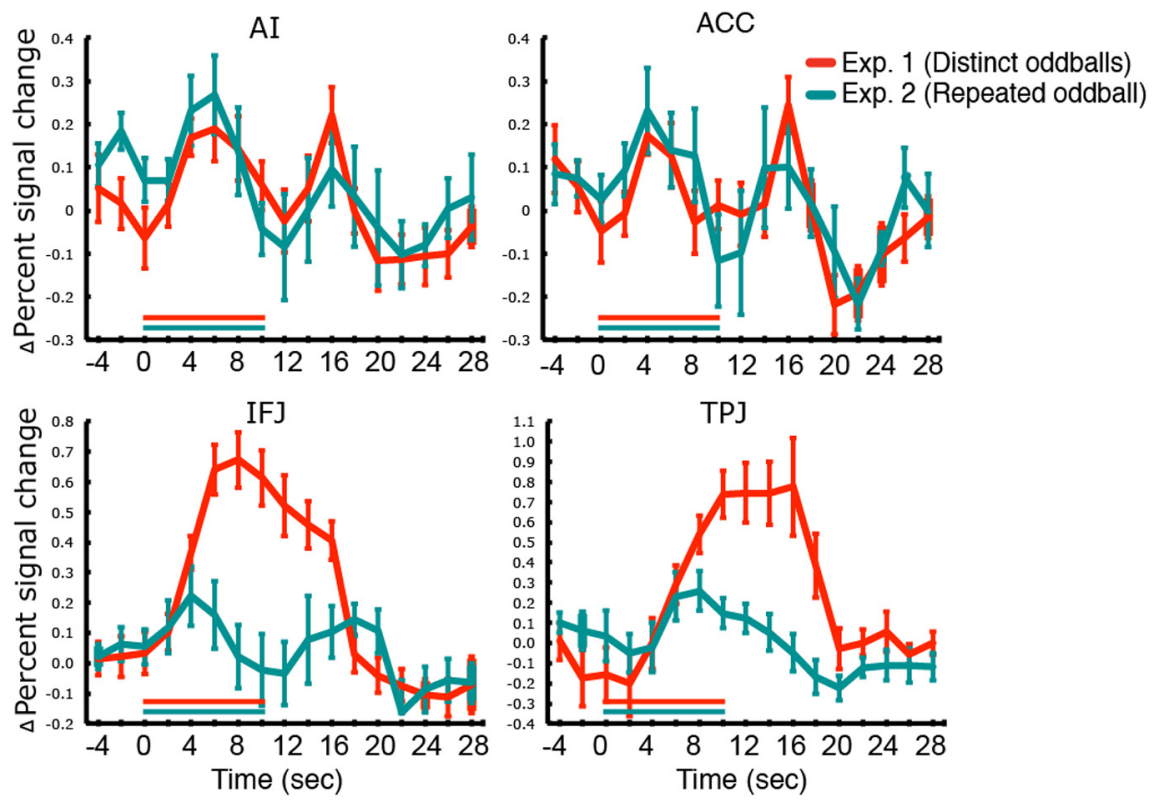

Figure 6. BOLD activity time courses of the AI, ACC, IFJ, and TPJ to repeated presentation of the same oddball in Experiment 2. For comparison, time courses of activity to unrepeated, distinct oddballs from Experiment 1 are also plotted. The red and green horizontal lines in the time courses indicate $10 \mathrm{~s}$ long presentations of distinct and repeated oddballs, respectively. Error bars represent SEM.

in goal-directed attention, the FEF and IPS (Kastner et al., 1999; Ikkai and Curtis, 2008; Asplund et al., 2010). Furthermore, the duration of such activity would be considerably reduced when the same oddball is repeatedly presented in Experiment 2, as it does not sustain subjects' attention (Fig. 1). Consistent with these predictions, the FEF and IPS showed sustained activity throughout the presentation duration of distinct oddballs, (middle point amplitudes above baseline, $p<0.005$, with no differences between the middle point and onset/offset amplitudes, $p>0.56$ ), whereas the activity tapered off much earlier with the repeated presentation of the same oddball, (ANOVA, significant main effects of experiment and time and an interaction between time and experiment, $p<0.005$; Fig. 7 ).

These IPS/FEF findings suggest that the dorsal parieto-frontal network supports the attentional demands of evaluation, consistent with studies showing that processing of salient, taskirrelevant oddballs recruits activation of brain regions involved in top-down attention (Bledowski et al., 2004; Yucel et al., 2007; SanMiguel et al., 2008).

\section{Amygdala}

We also examined how the amygdala responded to long oddballs because, apart from its role in affective processing (Adolphs et al., 1994; Phelps and LeDoux, 2005), this brain structure has also been implicated in processing of novel, salient stimuli (Wright et al., 2003; Kiehl et al., 2005; Blackford et al., 2010; Balderston et al., 2011). Given that none of the SPM analyses showed significant activation in the amygdala, this region was defined anatomically for each individual participant in both fMRI experiments. Similar to the TPJ, the amygdala showed a single-peaked response to the long oddball (Fig. 8); amplitude of the middle point was above baseline $(p<0.05)$, and there was no significant amplitude difference between the middle point and the onset $(p>0.40)$ and offset $(p>0.09)$. However, whereas the TPJ activity was strongly attenuated when the same oddball was repeatedly presented (see above), no such modulation of activity with repeated presenta- tions was found; a two-way ANOVA with time (11 TRs from the oddball onset) as a within-subject factor and oddball-type (distinct vs repeated) as a between-subject factor yielded no interaction $(p>0.94$; Fig. 8). This functional dissociation across these regions was further demonstrated by a three-way interaction between time, regions (TPJ vs amygdala) and oddball-type $\left(F_{(10,180)}=4.04, p<\right.$ $\left.5.16 \times 10^{-5}\right)$.

A final analysis considered whether the amygdala's response was driven by the potential affective contents of some of the oddball stimuli (e.g., a car accident or a dogfight between jet fighter). To address this issue, we probed the amygdala with oddball trials devoid of affective content (movie clips depicting fireworks, toys, laptops, and abstract animations, such as fractals, smoke, and molecular polymerization), while excluding the trials with any emotionarousing oddballs. Given that the same pattern of activation was observed as with all the oddballs (Fig. 8), we conclude that the amygdala's response to our stimuli was caused by their oddball nature rather than by their affective contents per se.

\section{Discussion}

The current study provides clear evidence for a functional dissociation of each region implicated in stimulus-driven attention, and yields important insights about how those regions contribute to human cognition in general.

The surprising finding that the AI (and dorsal ACC) was activated only by the onset and offset of the extended oddballs implicates this region in the transient process of attention orienting. Due to its association with a plethora of behavioral functions ranging from attention and perception to socio-affective processes, the AI's role in cognition has been extensively debated (Craig, 2002; Downar et al., 2002; Dosenbach et al., 2006, 2007; Sridharan et al., 2008; Menon and Uddin, 2010; Nelson et al., 2010; Touroutoglou et al., 2012). Several groups of researchers posit that the AI, in concert with the ACC, is primarily involved in the capture of focal attention either by a novel, salient stimulus (Seeley et al., 2007; Menon and Uddin, 2010) or by task-related stimuli (Dosenbach et al., 2006, 2007; Nelson et al., 2010), and may be involved in the implementation/maintenance of task sets (Dosenbach et al., 2006, 2007; Nelson et al., 2010). According to these views, socio-affective events or stimuli recruit the AI simply because they are salient or behaviorally significant (Menon and Uddin, 2010). The present finding that the AI is primarily involved in attentional orienting during oddball presentations is consistent with the attention account of this brain region (Nelson et al., 2010). The similar activation pattern in dACC also support its involvement in attentional orienting (Rushworth et al., 2002a,b; Woldorff et al., 2004; Taylor et al., 2008). Indeed, our study provides direct empirical evidence that the AI and dACC have similar functional roles in processing of salient stimuli, consistent with the claim that together they form a salience network (Dosenbach et al., 2007; Seeley et al., 2007; Sridharan et al., 2008). Finally, the transient nature of the AI and ACC's responses favor 
the interpretation that these two regions are conjointly involved in the transient capture of focal attention rather than in the maintenance of task sets per se. Evidently, further investigations are required to determine the specific computations performed by the two core regions of the salience network, and to elucidate whether they are involved in detecting salient stimuli per se, and/or in shifting the focus of attention to or from salient events.

Contrary to the AI and ACC, the TPJ and IFJ showed sustained activity during the long oddball presentations. The goal-directed attention analyses (Fig. 5) suggest that, at least for the TPJ, this sustained activity does not simply represent attention per se. Similarly, the observation that the TPJ failed to show dual-peak responses to oddball onsets and offsets is inconsistent with it being involved in attention orienting. Indeed, exhaustive examination of group or individual SPMs revealed that no region of inferior parietal cortex, including all three subregions of the TPJ identified by Mars et al. (2012), exhibited transient activity to these long oddballs. This finding is remarkable, especially given that this region has been implicated in attentional orienting/reorienting (Corbetta and Shulman, 2002; Corbetta et al., 2008; Ptak, 2012). The sustained TPJ activity challenges this predominant model, suggesting instead that the TPJ has other functional roles than orienting.

We propose that the TPJ's involvement in SDA primarily reflects an evaluative process rather than attention orienting. The orienting account may have been favored in previous attention studies because of the conventional use of brief stimulus presentations to interrogate TPJ function (Corbetta et al., 2000; Serences et al., 2005). Although the specific computation(s) underlying evaluation remain to be clarified, it is well established that such an evaluative process is distinct from attentional orienting, and that it should include elucidating the meaning and behavioral significance of a stimulus or event, possibly by comparing external events with internal models and predictions (Decety and Lamm, 2007; Summerfield and Egner, 2009; Doricchi et al., 2010; Geng and Mangun, 2011; Diquattro et al., 2013). This hypothesis fits well with recent studies pointing to a role of the TPJ in computing behavioral relevance of a stimulus or matching it to target templates (Doricchi et al., 2010; Geng and Mangun, 2011; Nardo et al., 2011). Furthermore, an evaluative function account of the TPJ can also explain why the TPJ is commonly engaged in mentalization, social evaluation, target identification, and oddball processing (Downar et al., 2002; Frith and Frith, 2006; Decety and Lamm, 2007; Cabeza et al., 2012). Based on previous studies of TPJ function, we further surmise that the evaluative process specifically consists in comparing the continuously unfolding oddball event with internal representations to gauge its potential behavioral significance (McCarthy and Donchin, 1981; Decety and Lamm, 2007; Polich, 2007; Geng and Mangun, 2011). This hypothesis is consistent with the markedly reduced activation observed in this brain region as the oddball content becomes familiar with repeated presentations. Finally, the evaluative account is not inconsistent with findings that three subregions of the TPJ may be connected to partly distinct cortical networks (Mars et al., 2012); we suggest that the same fundamental evaluative computation is performed by all three subregions but in the service of different cognitive processes (such as, mentalization, target detection, and oddball identification) implemented in these different networks. Although evidently speculative at this point, this hypothesis merits further investigation considering that, like the AI, the TPJ has been associated with widely disparate func-
Table 2. List of ROIs defined in Experiment 2

\begin{tabular}{lcrrr}
\hline & & \multicolumn{3}{c}{ Mean Talairach coordinates } \\
\cline { 3 - 5 } ROI name & Mean $t$ value & \multicolumn{1}{c}{$Y$} & 22 & $Z$ \\
\hline Left AI & 5.85 & -34 & 23 & -4 \\
Right AI & 7.27 & 30 & 14 & 0 \\
ACC & 7.42 & -4 & 2 & 41 \\
Left IFJ & 6.17 & -42 & 9 & 31 \\
Right IFJ & 9.78 & 37 & -57 & 29 \\
Left TPJ & -5.34 & -49 & -57 & 22 \\
Right TPJ & -3.00 & 42 & -7 & 30 \\
Left FEF & 5.33 & -34 & 5 & 55 \\
Right FEF & 6.66 & 34 & -63 & 48 \\
Left IPS & 6.32 & -29 & -64 & 40 \\
Right IPS & 12.73 & 25 & 40 \\
\hline
\end{tabular}

The ROIs were isolated from an SPM isolating activity associated with target presentation $(q(\mathrm{FDR})<0.05)$, similar to Experiment 1.

Table 3. Anatomical locations of the IFJ in the current study and previous studies

\begin{tabular}{|c|c|c|c|c|}
\hline & & Talairz & rdinat & \\
\hline & ROI name & $x$ & $\gamma$ & Z \\
\hline Current study & & & & \\
\hline Single-short oddball ROIs & Left IFJ & -49 & 19 & 18 \\
\hline & Right IFJ & 45 & 14 & 19 \\
\hline Target-defined ROls & Left IFJ & -45 & 3 & 22 \\
\hline & Right IFJ & 44 & 5 & 26 \\
\hline (Asplund et al., 2010) & & & & \\
\hline Oddball-defined ROls & Left IFJ & -40 & 8 & 25 \\
\hline & Right IFJ & 37 & 5 & 29 \\
\hline Goal-directed search ROls & Left IFJ & -42 & 8 & 25 \\
\hline & Right IFJ & 40 & 6 & 27 \\
\hline (Brass and von Cramon, 2002) & & & & \\
\hline Attentional cue-defined ROls & Left IFJ & -40 & -1 & 32 \\
\hline & Right IFJ & 44 & -1 & 38 \\
\hline (Dux et al., 2006) & & & & \\
\hline Goal-directed attention ROls & Left IFJ & -37 & 14 & 25 \\
\hline & Right IFJ & 42 & 18 & 28 \\
\hline (Han and Marois, 2013) & & & & \\
\hline Goal-directed attention ROls & Left IFJ & -47 & 4 & 23 \\
\hline & Right IFJ & 45 & 4 & 26 \\
\hline (Sneve et al., 2013) & & & & \\
\hline Working memory encoding ROls & Left IFJ & -44 & 3 & 33 \\
\hline & Right IFJ & 45 & 1 & 35 \\
\hline
\end{tabular}

Typically, the IFJ is located in the junction between the inferior frontal sulcus/gyrus and precentral sulcus (Brass et al., 2005).

tions (Decety and Lamm, 2007; Mitchell, 2008; Cabeza et al., 2012; Meyer et al., 2012).

Although the present study does not directly test the evaluation hypothesis, several previous studies support the proposition that the evaluative process subserved by the TPJ entails a dynamic interaction between external sensory stimuli and internal representations, which is separable from attention. Specifically, Cabeza et al. $(2008,2011)$ suggested that this ventral parietal region is primarily involved in the retrieval of information stored in memory, rather than attentional orienting. Similarly, Summerfield and Egner (2009) stressed a critical role of internal representations in interpreting sensory information. In their framework, the specific meaning of sensory information is extracted based upon prediction or context, and attention supports this process. These studies are not only compatible with our findings, they also provide insights into the nature of the evaluative process and distinguish it from attentional processes.

In addition to the TPJ, the amygdala also showed singlepeaked activity to the long oddball. However, the amygdala ac- 
tivity was immune to the demand for the evaluative process of the oddball contents (as its response was unaffected by repeated presentation of the same oddball), which the TPJ activity was strongly sensitive to. This finding suggests that the amygdala's response to the oddball may be primarily signaling an arousal response to a rare, salient event, rather than the cognitive evaluation of that event (Gläscher and Adolphs, 2003; Weierich et al., 2010).

Finally, the IFJ was the only region that clearly showed both transient and sustained activity. Notably, this region, which plays multiple roles in stimulusdriven attention in the present study, spatially overlaps with the region suggested to be a hub or coordinator of multiple cognitive processes (Brass et al., 2005; Dux et al., 2006; Asplund et al., 2010; Cole et al., 2013; Han and Marois, 2013; Sneve et al., 2013; Tables 1, 2, 3). Considering the involvement of this region in task switching and attentional control (Braver et al., 2003; Chiu and Yantis, 2009; Asplund et al., 2010), the transient activity likely reflects the attention shifts between the goal-directed task and oddball stimuli. Although the sustained activity is consistent with an involvement in stimulus evaluation/interpretation (Woldorff et al., 2004), it is also possible that it reflects sustained attention toward the oddball stimuli, especially considering that this brain region is also engaged in goal-oriented attention in consortium with the dorsal (FEF, IPS) regions (Asplund et al., 2010). The notion that IFJ may play multiple roles in stimulusdriven attention further points to its role as a central hub for attentional control (Konishi et al., 1998; Braver et al., 2003; Brass et al., 2005; Marois and Ivanoff, 2005; Asplund et al., 2010). Moreover, recent functional connectivity studies (Cole et al., 2013; Sneve et al., 2013) argue that the IFJ and adjacent lateral prefrontal areas are involved in controlling the flow of information in other brain regions and networks during the performance of cognitive tasks. Hence, we propose that the IFJ may coordinate or integrate the transient and sustained processes going on in the AI/ACC, TPJ, and dorsal brain regions during stimulus-driven attention. In that framework, the AI/ ACC are associated with attentional orienting, the dorsal regions sustain attention to the oddball stimuli, the TPJ is involved in evaluating the contents of the attended stimuli, while the IFJ acts to coordinate information flow across all these brain regions. Though speculative, this model provides a testable framework of the brain processes by which events succeed in capturing our attention.

\section{References}

Adolphs R, Tranel D, Damasio H, Damasio A (1994) Impaired recognition of emotion in facial expressions following bilateral damage to the human amygdala. Nature 372:669-672. CrossRef Medline

Asplund CL, Todd JJ, Snyder AP, Marois R (2010) A central role for the lateral prefrontal cortex in goal-directed and stimulus-driven attention. Nat Neurosci 13:507-512. CrossRef Medline

Balderston NL, Schultz DH, Helmstetter FJ (2011) The human amygdala
Exp. 1 (Distinct oddballs) - Exp. 2 (Repeated oddball)
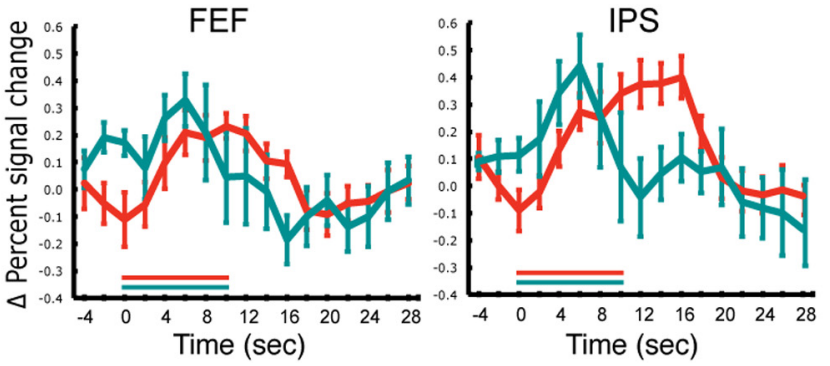

Figure 8. Anatomical location of the amygdala $\operatorname{ROI}(\boldsymbol{A})$ and its time course of activity to the long oddballs in Experiments 1 and

B

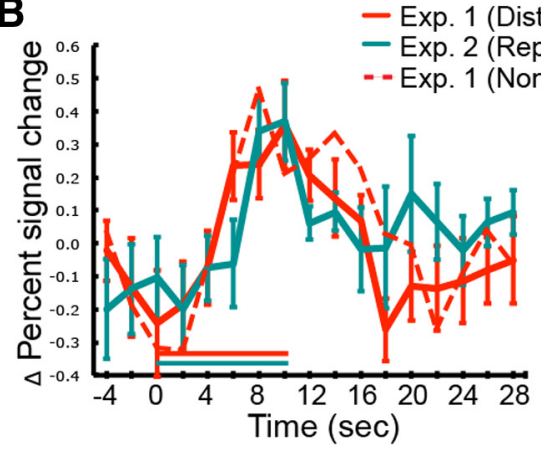

plays a stimulus specific role in the detection of novelty. Neuroimage 55:1889-1898. CrossRef Medline

Bartolomeo P, de Schotten TM, Chica AB (2012) Brain networks of visuospatial attention and their disruption in visual neglect. Front Hum Neurosci 6:110. CrossRef Medline

Blackford JU, Buckholtz JW, Avery SN, Zald DH (2010) A unique role for the human amygdala in novelty detection. Neuroimage 50:1188-1193. CrossRef Medline

Bledowski C, Prvulovic D, Hoechstetter K, Scherg M, Wibral M, Goebel R, Linden DE (2004) Localizing P300 generators in visual target and distractor processing: a combined event-related potential and functional magnetic resonance imaging study. J Neurosci 24:9353-9360. CrossRef Medline

Brass M, von Cramon DY (2002) The role of the frontal cortex in task preparation. Cereb Cortex 12:908-914. CrossRef Medline

Brass M, Derrfuss J, Forstmann B, von Cramon DY (2005) The role of the inferior frontal junction area in cognitive control. Trends Cogn Sci 9:314-316. CrossRef Medline

Braver TS, Reynolds JR, Donaldson DI (2003) Neural mechanisms of transient and sustained cognitive control during task switching. Neuron 39: 713-726. CrossRef Medline

Cabeza R, Ciaramelli E, Olson IR, Moscovitch M (2008) The parietal cortex and episodic memory: an attentional account. Nat Rev Neurosci 9:613625. CrossRef Medline

Cabeza R, Mazuz YS, Stokes J, Kragel JE, Woldorff MG, Ciaramelli E, Olson IR, Moscovitch M (2011) Overlapping parietal activity in memory and perception: evidence for the attention to memory model. J Cogn Neurosci 23:3209-3217. CrossRef Medline

Cabeza R, Ciaramelli E, Moscovitch M (2012) Cognitive contributions of the ventral parietal cortex: an integrative theoretical account. Trends Cogn Sci 16:338-352. CrossRef Medline

Chiu YC, Yantis S (2009) A domain-independent source of cognitive control for task sets: shifting spatial attention and switching categorization rules. J Neurosci 29:3930-3938. CrossRef Medline

Cohen J (1988) Statistical power analysis for the behavioral sciences, Ed 2. Hillsdale, NJ: Lawrence Earlbaum Associates.

Cole MW, Reynolds JR, Power JD, Repovs G, Anticevic A, Braver TS (2013) 
Multi-task connectivity reveals flexible hubs for adaptive task control. Nat Neurosci 16:1348-1355. CrossRef Medline

Corbetta M, Shulman GL (2002) Control of goal-directed and stimulusdriven attention in the brain. Nat Rev Neurosci 3:201-215. Medline

Corbetta M, Kincade JM, Ollinger JM, McAvoy MP, Shulman GL (2000) Voluntary orienting is dissociated from target detection in human posterior parietal cortex. Nat Neurosci 3:292-297. CrossRef Medline

Corbetta M, Patel G, Shulman GL (2008) The reorienting system of the human brain: from environment to theory of mind. Neuron 58:306-324. CrossRef Medline

Craig AD (2002) How do you feel? Interoception: The sense of the physiological condition of the body. Nat Rev Neurosci 3:655-666. Medline

Decety J, Lamm C (2007) The role of the right temporoparietal junction in social interaction: how low-level computational processes contribute to meta-cognition. Neuroscientist 13:580-593. CrossRef Medline

Diquattro NE, Sawaki R, Geng JJ (2013) Effective connectivity during feature-based attentional capture: evidence against the attentional reorienting hypothesis of TPJ. Cereb Cortex, in press. CrossRef Medline

Doricchi F, Macci E, Silvetti M, Macaluso E (2010) Neural correlates of the spatial and expectancy components of endogenous and stimulus-driven orienting of attention in the Posner task. Cereb Cortex 20:1574-1585. CrossRef Medline

Dosenbach NU, Visscher KM, Palmer ED, Miezin FM, Wenger KK, Kang HC, Burgund ED, Grimes AL, Schlaggar BL, Petersen SE (2006) A core system for the implementation of task sets. Neuron 50:799-812. CrossRef Medline

Dosenbach NU, Fair DA, Miezin FM, Cohen AL, Wenger KK, Dosenbach RA, Fox MD, Snyder AZ, Vincent JL, Raichle ME, Schlaggar BL, Petersen SE (2007) Distinct brain networks for adaptive and stable task control in humans. Proc Natl Acad Sci U S A 104:11073-11078. CrossRef Medline

Downar J, Crawley AP, Mikulis DJ, Davis KD (2002) A cortical network sensitive to stimulus salience in a neutral behavioral context across multiple sensory modalities. J Neurophysiol 87:615-620. Medline

Dux PE, Ivanoff J, Asplund CL, Marois R (2006) Isolation of a central bottleneck of information processing with time-resolved fMRI. Neuron 52: 1109-1120. CrossRef Medline

Eckert MA, Menon V, Walczak A, Ahlstrom J, Denslow S, Horwitz A, Dubno JR (2009) At the heart of the ventral attention system: the right anterior insula. Hum Brain Mapp 30:2530-2541. CrossRef Medline

Forman SD, Cohen JD, Fitzgerald M, Eddy WF, Mintun MA, Noll DC (1995) Improved assessment of significant activation in functional magnetic resonance imaging (fMRI): use of a cluster-size threshold. Magn Reson Med 33:636-647. CrossRef Medline

Frith CD, Frith U (2006) The neural basis of mentalizing. Neuron 50:531534. CrossRef Medline

Geng JJ, Mangun GR (2011) Right temporoparietal junction activation by a salient contextual cue facilitates target discrimination. Neuroimage 54: 594-601. CrossRef Medline

Gläscher J, Adolphs R (2003) Processing of the arousal of subliminal and supraliminal emotional stimuli by the human amygdala. J Neurosci 23: 10274-10282. Medline

Greicius MD, Krasnow B, Reiss AL, Menon V (2003) Functional connectivity in the resting brain: a network analysis of the default mode hypothesis. Proc Natl Acad Sci U S A 100:253-258. CrossRef Medline

Ham T, Leff A, de Boissezon X, Joffe A, Sharp DJ (2013) Cognitive control and the salience network: an investigation of error processing and effective connectivity. J Neurosci 33:7091-7098. CrossRef Medline

Hampton AN, Bossaerts P, O'Doherty JP (2008) Neural correlates of mentalizing-related computations during strategic interactions in humans. Proc Natl Acad Sci U S A 105:6741-6746. CrossRef Medline

Han SW, Marois R (2013) Dissociation between process-based and databased limitations for conscious perception in the human brain. Neuroimage 64:399-406. CrossRef Medline

Harrison BJ, Pujol J, López-Solà M, Hernández-Ribas R, Deus J, Ortiz H, Soriano-Mas C, Yücel M, Pantelis C, Cardoner N (2008) Consistency and functional specialization in the default mode brain network. Proc Natl Acad Sci U S A 105:9781-9786. CrossRef Medline

Ikkai A, Curtis CE (2008) Cortical activity time locked to the shift and maintenance of spatial attention. Cereb Cortex 18:1384-1394. CrossRef Medline

Kahneman D (1973) Attention and effort. New York: Prentice Hall.
Kastner S, Pinsk MA, De Weerd P, Desimone R, Ungerleider LG (1999) Increased activity in human visual cortex during directed attention in the absence of visual stimulation. Neuron 22:751-761. CrossRef Medline

Kiehl KA, Stevens MC, Laurens KR, Pearlson G, Calhoun VD, Liddle PF (2005) An adaptive reflexive processing model of neurocognitive function: supporting evidence from a large scale $(n=100)$ fMRI study of an auditory oddball task. Neuroimage 25:899-915. CrossRef Medline

Konishi S, Nakajima K, Uchida I, Kameyama M, Nakahara K, Sekihara K, Miyashita Y (1998) Transient activation of inferior prefrontal cortex during cognitive set shifting. Nat Neurosci 1:80-84. CrossRef Medline

Marois R, Ivanoff J (2005) Capacity limits of information processing in the brain. Trends Cogn Sci 9:296-305. CrossRef Medline

Mars RB, Sallet J, Schüffelgen U, Jbabdi S, Toni I, Rushworth MF (2012) Connectivity-based subdivisions of the human right "temporoparietal junction area": evidence for different areas participating in different cortical networks. Cereb Cortex 22:1894-1903. CrossRef Medline

McCarthy G, Donchin E (1981) A metric for thought: a comparison of P300 latency and reaction time. Science 211:77-80. CrossRef Medline

McCarthy G, Luby M, Gore J, Goldman-Rakic P (1997) Infrequent events transiently activate human prefrontal and parietal cortex as measured by functional MRI. J Neurophysiol 77:1630-1634. Medline

Menon V, Uddin LQ (2010) Saliency, switching, attention and control: a network model of insula function. Brain Struct Funct 214:655-667. CrossRef Medline

Meyer ML, Spunt RP, Berkman ET, Taylor SE, Lieberman MD (2012) Evidence for social working memory from a parametric functional MRI study. Proc Natl Acad Sci U S A 109:1883-1888. CrossRef Medline

Mitchell JP (2008) Activity in right temporo-parietal junction is not selective for theor-of-mind. Cereb Cortex 18:262-271. CrossRef Medline

Nardo D, Santangelo V, Macaluso E (2011) Stimulus-driven orienting of visuo-spatial attention in complex dynamic environments. Neuron 69: 1015-1028. CrossRef Medline

Nelson SM, Dosenbach NU, Cohen AL, Wheeler ME, Schlaggar BL, Petersen SE (2010) Role of the anterior insula in task-level control and focal attention. Brain structure and function 214:669-680. CrossRef Medline

Pavlov IP (1927) Conditioned reflexes. Oxford: Oxford UP.

Phelps EA, LeDoux JE (2005) Contributions of the amygdala to emotion processing: from animal models to human behavior. Neuron 48:175-187. CrossRef Medline

Polich J (2007) Updating P300: an integrative theory of P3a and P3b. Clin Neurophysiol 118:2128-2148. CrossRef Medline

Posner MI (1980) Orienting of attention. Q J Exp Psychol 32:3-25. CrossRef Medline

Ptak R (2012) The frontoparietal attention network of the human brain: action, saliency, and a priority map of the environment. Neuroscientist 18:502-515. CrossRef Medline

Raichle ME, MacLeod AM, Snyder AZ, Powers WJ, Gusnard DA, Shulman GL (2001) A default mode of brain function. Proc Natl Acad Sci U S A 98:676-682. CrossRef Medline

Rushworth MF, Passingham RE, Nobre AC (2002a) Components of switching intentional set. J Cogn Neurosci 14:1139-1150. CrossRef Medline

Rushworth MF, Hadland KA, Paus T, Sipila PK (2002b) Role of the human medial frontal cortex in task switching: a combined fMRI and TMS study. J Neurophysiol 87:2577-2592. Medline

SanMiguel I, Corral MJ, Escera C (2008) When loading working memory reduces distraction: behavioral and electrophysiological evidence from an auditory-visual distraction paradigm. J Cogn Neurosci 20:1131-1145. CrossRef Medline

Seeley WW, Menon V, Schatzberg AF, Keller J, Glover GH, Kenna H, Reiss AL, Greicius MD (2007) Dissociable intrinsic connectivity networks for salience processing and executive control. J Neurosci 27:2349-2356. CrossRef Medline

Serences JT (2004) A comparison of methods for characterizing the eventrelated BOLD timeseries in rapid fMRI. Neuroimage 21:1690-1700. CrossRef Medline

Serences JT, Shomstein S, Leber AB, Golay X, Egeth HE, Yantis S (2005) Coordination of voluntary and stimulus-driven attentional control in human cortex. Psychol Sci 16:114-122. CrossRef Medline

Shulman GL, Astafiev SV, McAvoy MP, d'Avossa G, Corbetta M (2007) Right TPJ deactivation during visual search: functional significance and 
support for a filter hypothesis. Cereb Cortex 17:2625-2633. CrossRef Medline

Sneve MH, Magnussen S, Alnæs D, Endestad T, D’Esposito M (2013) TopDown modulation from inferior frontal junction to FEFs and intraparietal sulcus during short-term memory for visual features. J Cogn Neurosci 25:1944-1956. CrossRef Medline

Sokolov EN (1963) Perception and the conditioned reflex. New York: Pergamon.

Sridharan D, Levitin DJ, Menon V (2008) A critical role for the right frontoinsular cortex in switching between central-executive and default-mode networks. Proc Natl Acad Sci U S A 105:12569-12574. CrossRef Medline

Summerfield C, Egner T (2009) Expectation (and attention) in visual cognition. Trends Cogn Sci 13:403-409. CrossRef Medline

Talairach J, Tournoux P (1988) Coplanar stereotaxic atlas of the human brain. New York: Thieme.

Taylor PC, Rushworth MF, Nobre AC (2008) Choosing where to attend and the medial frontal cortex: an FMRI study. J Neurophysiol 100:1397-1406. CrossRef Medline

Todd JJ, Fougnie D, Marois R (2005) Visual short-term memory load sup- presses temporo-parietal junction activity and induces inattentional blindness. Psychol Sci 16:965-972. CrossRef Medline

Touroutoglou A, Hollenbeck M, Dickerson BC, Feldman Barrett L (2012) Dissociable large-scale networks anchored in the right anterior insula subserve affective experience and attention. Neuroimage 60:1947-1958. CrossRef Medline

Weierich MR, Wright CI, Negreira A, Dickerson BC, Barrett LF (2010) Novelty as a dimension in the affective brain. Neuroimage 49:2871-2878. CrossRef Medline

Woldorff MG, Hazlett CJ, Fichtenholtz HM, Weissman DH, Dale AM, Song AW (2004) Functional parcellation of attentional control regions of the brain. J Cogn Neurosci 16:149-165. CrossRef Medline

Wright CI, Martis B, Schwartz CE, Shin LM, Fischer HH, McMullin K, Rauch SL (2003) Novelty responses and differential effects of order in the amygdala, substantia innominata, and inferior temporal cortex. Neuroimage 18:660-669. CrossRef Medline

Yucel G, McCarthy G, Belger A (2007) fMRI reveals that involuntary visual deviance processing is resource limited. Neuroimage 34:1245-1252. CrossRef Medline 